\title{
A (DE)PRESSÃO E A CONTEMPORANEIDADE: NOTAS SOBRE O SINTOMA SOCIAL
}

\section{THE DEPRESSION AND CONTEMPORANEITY: NOTES ABOUT THE SOCIAL SYMPTOM}

\author{
Marilene Moreira da Silva Magalhães*, Fábio Giorgio Santos Azevedo**
}

\begin{abstract}
Autora para correspondência: Marilene Moreira da Silva Magalhães - marilene_mm@hotmail.com
*Psicóloga pela Universidade Federal da Bahia (UFRB). Especialista em Saúde Mental e Atenção Básica pela Escola Bahiana de Medicina e Saúde Pública (EBMSP)

**Psicólogo graduado pela Universidade Federal da Bahia (UFBA). Especialista em Antropologia Visual

(UFBA) e Mestre em Educação (UFBA). Professor nas universidades Católica do Salvador (UCSAL), Salgado de Oliveira, e na Escola Bahiana de Medicina e Saúde Pública (EBMSP)
\end{abstract}

\section{R E S U M O}

\begin{abstract}
Na contemporaneidade, o predomínio de determinadas sintomatologias e formas de subjetivação podem estar intrinsecamente relacionadas com as características da cultura atual. $O$ presente trabalho tem como objetivo discutir sobre a depressão como sintoma social na contemporaneidade. Realizou-se um estudo teórico a partir da revisão de literatura com base em artigos e livros que tratam do tema em questão. Percebeu-se que a contemporaneidade se caracteriza por uma sociedade espetacular e narcísica, produtora de (de) pressões e solicitaçães por uma busca de gozo sem limites e satisfação a todo custo, o que tem se tornado árduo demais para os sujeitos. Nesse contexto, a depressão surge como um mal-estar que expressa o desacordo e o vazio de não corresponder aos ideais da cultura atual. A literatura consultada aponta ainda que o termo depressão tem sido usado como um significante para nomear diversos sentimentos, a exemplo da tristeza que tem sido aventada como sinônimo de depressão. Ao lado disso, foi possível reconhecer que a maioria dos casos diagnosticados como "depressão" nos dispositivos de saúde mental são tratados pela via da medicalização que, por vezes, considera prioritariamente o sintoma em detrimento do sujeito. Assim, concluiu-se que a escuta clínica, especificamente a psicanalítica, surge como uma alternativa à medicalização, a singularidade do sujeito no lugar do enfoque na patologia.
\end{abstract}

Palavras-chave: Depressão, sintoma social, psicanálise, contemporaneidade. 
In contemporary times, the predominance of some clinical symptoms and ways of subjectivities can be intrinsically related to the characteristics of the current culture. The present studies has a goal to discuss the depression as a social symptom in contemporary times. It was perform an academic study as from the literature review based on articles and books which deal with the present topic. It was noticed that the contemporary times is made of an amazing and narcissist society which is a producer of depression feelings and wishes for an enjoyment without limits and satisfaction at all costs, what has become too hard to the people. In this sense, the depression comes as a malaise that shows the disagreement and the emptiness to not correspond to the ideals of current culture. The consulted literature shows that the term depression has been used as a meaning to name several feelings, for example the sadness which has been suggested as a synonym for depression. Besides that, it was possible to recognize that the majority cases diagnosed as "depression" in the mental health devices are treated through the medication that sometimes considers as a priority the symptom rather than the individual. Thereby, it concludes that the clinic listening, specifically the psychoanalytic, comes up as an alternative of medication, the individual uniqueness instead of the focus on pathology.

Keywords: Depression, social symptom, psychoanalysis, contemporaneity. 


\section{INTRODUÇÃO}

O interesse pelo tema surge a partir do desejo de discutir sobre a depressão enquanto mal-estar que ocupa lugar de destaque na mídia, nas redes sociais, nos espaços acadêmicos e, principalmente, no contexto da saúde pública. No presente artigo, discutimos a depressão como sintoma social a partir de algumas características da contemporaneidade que podem ser disparadoras ou potencializadoras de mal-estar.

Para ○ escopo da discussão, inicialmente apresentamos algumas características da cultura atual a partir da ideia da sociedade de consumo e espetacular. Em seguida, discorremos sobre a depressão enquanto significante usado pelos sujeitos para nomear alguns sentimentos, a exemplo da tristeza, e sobre como a depressão é concebida pela via da psiquiatria e da psicanálise. Por último, discutimos acerca da escuta clínica, especificamente a psicanalítica, como uma das alternativas de tratamento para a depressão no contexto da saúde pública, face à excessiva patologização e medicalização do sofrimento do qual se queixam os depressivos e finalizamos com reflexões que pretendem suscitar novas indagações acerca do tema abordado. Desse modo, à guisa de introdução, vale destacar que a questão do mal-estar do sujeito já inquietava Freud'. Na perspectiva desse autor, na sua obra O Mal-estar na Civilização, o mal-estar dos sujeitos apontava para os descaminhos entre o que - mesmo desejara e o que a sociedade lhe exigia sendo o mal-estar próprio do sujeito na cultura, na medida em que a civilização seria construída sobre a renúncia das pulsões, buscando a sublimação no contexto civilizatório.

Em vista disso, pode-se compreender que o sujeito, na contemporaneidade, apresenta diversos modos de se posicionar no mundo diante das exigências da cultura da sua época, produzindo, por vezes, sintomas - a exemplo da depressão.

A cultura configura-se, então, como condição sine qua non na constituição do psiquismo humano, sendo inegável a relação desta com as sintomatologias que surgem em cada período. Em decorrência disso, algumas características fundamentais da contemporaneidade podem estar relacionadas ao surgimento de formas de mal-estares como a depressão, quais sejam: a liquidez nas ações, a desconfiança nos discursos, a fragmentação e o desamparo, ente outros.

As características da cultura contemporânea sociedade atual ganham contornos na esfera do consumo de imagens-objetos produzidos pela indústria e, por sua vez, o espetáculo surge como a principal produção da sociedade atual ${ }^{2}$. Por esse caminho e valendo-se de forma metafórica, dos termos (Modernidade Sólida e Modernidade Líquida) pode-se depreender as mudanças ocorridas na modernidade como uma produção histórica, social e cultural que têm impactado na sociedade atual e que podem ser produtoras e potencializadoras de fenômenos modificadores das formas de constituição das subjetividades ${ }^{3}$.

Assim, a depressão e suas variadas formas de classificação destacam-se enquanto fenômeno na atualidade, tendo em vista que esta se tornou um dos mitos em saúde mental na contemporaneidade ${ }^{4}$. Neste mesmo sentido, este mal-estar contemporâneo poderia estar relacionado a uma pluralidade de fatores característicos da cultura atual que determinam e perpetuam a depressão como uma das grandes modalidades de mal-estar na contemporaneidade.

Segundo dados da OMS (Organização Mundial de saúde) publicados no relatório mundial da Saúde - Saúde mental: nova concepção, nova esperança ${ }^{5}$ - a depressão, nos próximos vinte anos, poderia vir a ser a segunda das principais causas de doenças em todo o mundo, como também, uma das principais causas para o afastamento dos sujeitos de toda natureza de atividades laborais, contribuindo para impossibilitá-los de vivenciarem sua existência nas dimensões sociais e coletivas ${ }^{4}$.

Nesse contexto, o estudo da depressão parte de uma inquietação sobre a sua presença em nosso meio e chama a atenção o fato de existir uma preocupação crescente como estudo dessa temática, mobilizando o desenvolvimento de pesquisas a partir da compreensão desta como um sintoma do mal-estar na sociedade contemporânea ${ }^{4,7,8}$.

Vale destacar que 0 conceito de sintoma social utilizado aqui não se define em função da grande 
incidência ou relevância estatística da depressão como patologia, haja vista que não se almeje aqui priorizar esse aspecto. A ideia de sintoma social aqui utilizada seria a inscrição específica da articulação discursiva própria a tal sintoma (depressão) no discurso social, considerando que o significante em questão é usado na atualidade como rótulo para identificar e etiquetar as mais variadas formas de mal-estar ${ }^{6}$.

Por fim, as reflexões nesse trabalho podem contribuir para que os profissionais de saúde no contexto da saúde pública estejam mais sensíveis à escuta clínica nos dispositivos de saúde mental. Essa alternativa pode abrir espaço para a prática da escuta psicanalítica dos sujeitos que apresentam estados depressivos, possibilitando que 0 seu tratamento não se paute exclusivamente na medicalização da dor e da vida. Ao lado disso, pode favorecer que os sujeitos lidem melhor com os desafios que a existência humana se depara na contemporaneidade.

Para realização do trabalho empreendemos uma revisão de literatura, por meio de pesquisa bibliográfica de artigos e livros que tratassem do tema em questão. A pesquisa dos artigos foi feita prioritariamente nas principais bases de dados: ScientificEletronic Library Online (SCIELO); Periódicos Eletrônicos em Psicologia (PEPsic); Portal CAPES e Biblioteca Virtual em Saúde (BVS), utilizando os descritores: "depressão na contemporaneidade", "depressão como sintoma social", "mal-estar na contemporaneidade", "escuta psicanalítica na saúde mental", "psicanálise e saúde mental". Quanto aos critérios de inclusão e exclusão considerou-se prioritariamente os artigos publicados em Português, de 2006 a 2016. Posteriormente foi feita leitura sistemática do material selecionado e o registro das informações essenciais, levando em consideração os objetivos que a pesquisa propõe.

\section{DEPRESSÃO E CONTEMPORANEIDADE: A RECUSA DO SUJEITO FRENTE AO PALCO ESPETACULAR}

A depressão se configura como uma das modalidades de sofrimento predominantes na contemporaneidade. Partindo da ideia freudiana acerca do sofrimento psíquico, considera-se que não se pode dissociar o mal-estar psíquico do seu contexto social, haja vista que há uma incompatibilidade entre as necessidades individuais do homem frente às exigências sociais e culturais de sua época'.

Nessa perspectiva, as três fontes de sofrimento psíquico corresponderiam às questões inerentes à vida na civilização, "a prepotência da natureza, a fragilidade de nosso corpo e a insuficiência das normas que regulam os vínculos humanos na família, no Estado e na sociedade"!.

Partiremos deste último ponto para refletirmos sobre a depressão na contemporaneidade, considerando-a como expressão de um sintoma social, destacando algumas características específicas da cultural atual que podem ser disparadoras deste sintoma.

A evolução histórica de uma sociedade não ocorre sem deixar marcas que a caracterizam e que estão relacionadas aos modos de constituição das subjetividades individuais e coletivas que emergem nesse processo, já que "cada espécie de sociedade produz sua própria espécie de estranhos e a produz de sua própria maneira, inimitável" " No caso das sociedades moderno-ocidentais, a análise do mundo moderno pode ser compreendida a partir de dois períodos distintos: A Modernidade Sólida e a Modernidade Líquida'. A Modernidade Sólida seria marcada pela era do Hardware, das grandes máquinas, da lentidão da passagem do tempo e a Modernidade Líquida, estamparia a fluidez, a leveza e a instantaneidade, tão evidentes na relação tempo e espaço, como marca indubitável da ordem econômica capitalista que impera nesse período. A principal característica da era do software, seria "a viagem à velocidade da luz; o espaço pode ser atravessado, literalmente, em 'tempo nenhum'; cancela-se a diferença entre 'longe' e 'aqui'"

Durante a Modernidade Sólida, teria sido possível a construção de referenciais socioculturais que serviriam de fio condutor para a tessitura de laços sociais duradouros 9 . Nesse sentido, os laços socais familiares na passagem da era pré-moderna para a modernidade possuíam características marcantes como o convívio no mesmo espaço de diferentes gerações e a autoridade do pai era quase absoluta e incontestável ${ }^{10}$. As transformações apresentadas pela estrutura familiar desde então reflete novas 
configurações de laço socais que se formariam a partir da constituição de espaços de privacidade, novos arranjos familiares, entre outros aspectos que caracterizariam às mudanças ocorridas na era moderna $^{10}$.

Assim, consideremos a contemporaneidade como herdeira dos referenciais postos na Modernidade Líquida que se traduz na ideia de liquidez e de fluidez, sendo percebida no modo como as relações familiares, interpessoais, de trabalho, entre outras, são constituídas na atualidade, colocando à prova as certezas e os referenciais outrora construídos sob um modo de atadura social na Modernidade Sólida $^{3}$. Na contemporaneidade, os ideais, as tradições, a autoridade paterna e as religiões perderam sua importância, favorecendo que os sujeitos criem maneiras diversas de se posicionar diante das solicitações e mudanças dos contextos social, econômico e cultural. "Se o sujeito não atinge os ideais proclamados pela sociedade, nada mais Ihe resta senão sua condição de exclusão, de doente" 11 .

Nesse sentido, à cultura capitalista promoveria no sujeito a ideia de que pode ser autossuficiente e, de forma individual, enfrentar os reveses postos pela vida em sociedade.

Vivemos sob o domínio do discurso capitalista, em que os homens não se cercam mais de outros homens e sim de objetos produzidos pela tecnologia; suas relações sociais não estão centradas nos laços com outros homens, mas na manipulação de mercadorias e mensagens. Essa deterioração dos laços sociais e o empuxo ao prazer solitário, realizando a economia do desejo do Outro, estimulam a ilusão da completude não mais com um par, porém com um parceiro conectável e desconectável ao alcance das mãos ${ }^{12}$.

Os aspectos da cultura contemporânea, avulta a ideia da homogeneização desta ao jogo de imagens, sons e encurtamento do tempo-espaço, como aspectos intrínsecos ao que se conhece hoje como 'sociedade do espetáculo' ${ }^{2}$. Tem-se um cenário em que os sujeitos podem utilizar os objetos de consumo disponíveis no mercado capitalista e, desse modo, sustentarem a fantasia de que podem atuar satisfatoriamente no palco forjado socialmente, onde os holofotes estão voltados para si. "O que aparece é bom, o que é bom aparece. "3

Com isso, aqueles que não conseguem estetizar sua existência a ponto de ganhar prestígio social, buscam a exaltação de si mediante "a melhor performance possível, o modelo desejado socialmente de imagem, os bens (tecnologias - objetos móveis e imóveis) que estão expostos nesse cenário espetacular" ${ }^{13}$. Ocorre então que do consumo direcionado às necessidades passou-se ao consumo direcionado à tentativa da satisfação de desejos, instalando-se para o sujeito uma falsa sensação de que pode ser e ter tudo, pois na cultura do espetáculo o fracasso não tem vez e o que se busca é o gozo pleno.

Desse modo, os destinos do desejo no atual cenário contemporâneo, assumem, pois, uma direção notadamente exibicionista e autocentrada, haja vista que $\circ$ horizonte intersubjetivo se encontra esvaziado e desinvestido das trocas entre os sujeitos. Nessa direção, pode-se pensar que "a era da individualidade substituiu a da subjetividade, dando a si mesmo a ilusão de uma liberdade irrestrita, de uma independência sem desejo e historicidade sem história ${ }^{13}$.

Depreende-se, com base no exposto, que, na cultura atual, o sujeito adere à promessa de prazer imediato ofertada pelo consumo, da plena liberdade de escolha diante das variadas possibilidades que se apresentam aos indivíduos, mas que, de certa forma, já são vazias de referenciais sólidos. Nesse contexto, os sujeitos podem se sentir inseguros por não saberem lidar com a ilusão de liberdade posta pelos contextos socioeconômico e cultural. Diante disso, o cenário capitalista, transitório e fluido, apresentado ao sujeito, remete a uma condição de desamparo, visto que os valores nesse cenário são rapidamente consumidos e substituídos por outros tão fluidos quanto os primeiros, gerando angústia?.

Isso leva a crer que na sociedade atual, a emergência de sintomatologias, a exemplo da depressão, poderia estar relacionada às primeiras experiências vivenciadas na infância, que, via de regra, se estruturam a partir de "um objeto externo qualquer que é buscado com a finalidade de preencher o vazio insuportável"14.

É nesse sentido que Freud ${ }^{15}$ menciona as tentativas dos sujeitos na vida adulta de se mostrar incapaz de abrir mão de uma sensação prazerosa que outrora desfrutou na infância buscando evitar desesperadamente as sensações de mal-estar, 
tal qual fazia nesse período, quando ainda não possuía uma representação que tornasse suportável a dor e a frustração da espera, ou da negociação do objeto:

Ele não está mais disposto a renunciar a perfeição narcisista da sua infância; e quando, ao crescer, se vê perturbado pelas admoestações de terceiros e pelo despertar de seu próprio julgamento crítico, de modo a não mais poder reter aquela perfeição, procura-se recuperá-la sob a forma de um ego ideal ${ }^{15}$.

A percepção sobre mais essa função narcísica dos sujeitos faz referência à formação de um ideal e a sublimação das pulsões. Entretanto, um homem que tenha trocado seu narcisismo para abrigar um ideal de ego elevado nem sempre foi bem-sucedido em sublimar seus instintos libidinais, haja vista que na infância haveria todo um investimento materno na criança, atendendo aos seus pedidos de satisfação e, por conseguinte, para viver na cultura os sujeitos teriam que se haver com imposições sociais frente ao seu desejo ${ }^{15}$. Desse modo, é que podemos pensar que os sujeitos na atualidade buscariam sustentar a ilusão de puder preencher o que lhes 'falta', não reconhecendo essa como constitutiva a existência humana. Assim, a cada conquista formula-se nova demanda, novo desejo, ocasionando por vezes, insatisfações em função dos sujeitos não alcançarem a completude dos desejos e experienciando, por vezes, desse modo, sentimentos de desemparo, tristeza.

É por esse caminho circunscrito entre a dinâmica das pulsões e do sintoma, que se tem o encontro entre duas poderosas forças, uma que busca se livrar do sintoma e outra que se satisfaz com o sintoma. $O$ sujeito que faz sintoma de um modo, pode até mesmo tentar tamponar o escape de certo comportamento de sofrimento, mas esse sofrimento retornará nas diferentes formas, até que o sujeito venha a se haver com o que lhe faz sofrer ${ }^{16}$.

A organização do campo social na atualidade, seria nesse sentido, tributária dos ideais sociais, que, em última instância, são formações imaginárias organizadoras do campo social, variando de cultura para cultura. É desse modo, que se pode pensar no vazio ao qual se referem os deprimidos, tendo em vista que a sociedade atual privilegiaria a vida privada, a competitividade, a satisfação dos desejos a todo custo pela via do consumo, ratificando desse modo os imperativos de perfeição, beleza, juventude e de felicidade plena ${ }^{7}$.

A depressão portaria, desse modo, um sofrimento psíquico vivenciado pelos sujeitos, marcado pela dificuldade de colocar a termo sua própria condição transitória, de incompletude e finitude, referenciada em um narcisismo ideal que não consegue responder aos impasses da onipotência perdida frente a exigência de performance social da cultura do espetáculo que se apresenta aos sujeitos contemporâneos ${ }^{17}$. Nesse contexto, podese pensar que os sujeitos modernos sofreriam em função da busca por outros ideais, que se pautariam entre o que se é e como deveria ser, entre $\circ$ que sem tem e $\circ$ que se deveria ter. Dito de outro modo, os ideais dos sujeitos na atualidade se diferenciaram dos ideais dos sujeitos da época de Freud, considerando que os ideais dos sujeitos na atualidade estariam modificando-se em função da busca pela melhor performance na vida em cultura. Até aqui, seria possível depreender que os mal-estares supostamente interpretados como depressão poderiam ser uma reação subjetiva do sujeito contemporâneo frente às demandas da cultura do espetáculo e do narcisismo.

Nessa perspectiva, o sintoma, ao emergir, teria como função revelar um sujeito que se encontra à mercê de si mesmo e do seu desejo, referenciado nas vicissitudes da crença narcísica e no sofrimento diante de sua própria condição transitória. Ao lado disso e, considerando ainda que o sintoma " é estruturado como linguagem"18, este seria em última instância, simbolicamente, um resultante que expressaria um conflito psíquico ao modo de uma solução de compromisso entre o desejo e a defesa. Assim, é na defesa contra o sofrimento que habitaria o próprio "mal-estar"1.

Desse modo, percebe-se que na contemporaneidade ○ significante "depressão", não raro, é usado corriqueiramente como rótulo para nomear sentimentos que dizem de mal-estares. Esses sentimentos, por vezes, fariam referência à impotência do sujeito em lidar com as dores e as incertezas do existir, evidenciando uma modalidade específica de sofrimento psíquico muito frequente e cada vez mais presente. 


\section{DEPRESSÃO: A DOR QUE TEM NOME?}

Tristeza, desesperança, desamparo e desânimo são alguns dos sentimentos que estão presentes nos discursos dos sujeitos contemporâneoscomo expressão de mal-estar. A tristeza pode ser compreendida, por vezes, como sinônimo de depressão. $O$ significante "depressão" tem sido comumente usado de forma genérica na contemporaneidade para nomear os sentimentos que expressam o desacordo dos sujeitos com $\circ$ ideal de felicidade e de satisfação tão valorizados socialmente ${ }^{7}$. Interessante observar que "o significante "depressão" parece ter engendrado o batalhão de sujeitos que assim qualifica sev estado d'alma quando se encontram tristes, desanimados, frustrados, impotentes ou angustiados. "12

Nesse sentido, a partir do momento em que o sujeito se vê atrelado ao significante "depressão", este tem a ilusória sensação de que encontrou o diagnóstico para o seu mal-estar por meio de um significante que portaria o seu sofrimento expressando a sua dor ${ }^{19}$.

Ao tratar dessa questão e buscando-se compreender a natureza das depressões seria importante considerar a sua singularidade, haja vista que estados como tristeza, desânimo, inapetência para a vida, caracterizariam, por vezes, reações aos avatares da vida cotidiana, não pressupondo necessariamente estados depressivos, embora todos estes participem também do sofrimento dos sujeitos que vivenciam a depressão $0^{20}$.

A depressão, do mesmo modo como a angústia, a ansiedade, o medo, o pânico, as fobias e as paixões, enquanto phatos de uma forma geral, revelariam um sentimento de "mal-estar", por vezes indizível, indicando em última instância que algo no sujeito clama por uma possibilidade de elaboração subjetiva e compreensão interna ${ }^{7}$. O significado da palavra depressão teria, na sua carga semântica, a capacidade de magnificar a dor e o sofrimento. Desse modo, esse significante supostamente seria capaz de dar sentido ao nonsence e nomear $\circ$ inominável ${ }^{19}$.

É importante frisar que, tal como outros termos que definem diversas manifestações psicopatológicas trabalhadas pela psicanálise, o termo depressão não é originário desta, mas da psiquiatria, cujo significado está baseado em uma doença orgânica ${ }^{17}$.

A psiquiatria, concebida como o saber médico considera o sofrimento psíquico, como um desvio, como algo fora do padrão de normalidade, como doença e, de modo geral, concebe o sujeito como racional e consciente acerca do seu sofrimento. Utiliza referenciais biológicos para diagnosticar e nomear os fenômenos observáveis, que nessa perspectiva são classificados em categorias de CIDs (classificação internacional de doenças) e DSMs (manual diagnóstico e estatístico de transtornos mentais), desconsiderando, por vezes, a subjetividade e singularidade do sujeito ${ }^{20}$.

A depressão para a psiquiatria se caracterizaria por uma multiplicidade de sintomas afetivos, neurovegetativos, ideativos, cognitivos, entre outros, que serviriam para explicar seus principais elementos $^{21}$. As manifestações depressivas são classificadas em quadros que variam dos leves aos mais severos sendo também nomeadas como transtornos de humor e anedonia, por exemplo. Vale ressaltar que o tratamento da depressão pela psiquiatria buscaria a eliminação do sintoma visando a normalização do sujeito ${ }^{21}$.

Há de se considerar que o trabalho do médico na psiquiatra, por vezes, está pautado no modus operandis de uma sociedade governada pela ordem da fluidez, instantaneidade da produção e da produtividade. Desta forma, o uso de um psicofármaco cai como uma luva para uma sociedade que demanda atendimentos cada vez mais rápidos e que a lógica dos discursos predominantes sobre a depressão reflete sempre um ideal de saúde que obedece, por sua vez, a uma lógica consumista e mercadológica, típica da modernidade ${ }^{4}$.

Diferentemente da psiquiatria, para a psicanálise, - mal-estar psíquico do sujeito não seria visto como algo que precisa ser tratado exclusivamente pela via farmacológica, pois considera que o sujeito é atravessado pelo desejo, o sujeito do inconsciente, posição diversa do sujeito da certeza e da razão, por isso não busca a eliminação do sintoma, pois - manejo pela via da psicanálise tem como foco o trabalho com o sujeito e como este pode lidar com o seu sintoma. 
Vale destacar que Freud não teorizou especificamente sobre a depressão como uma estrutura clínica, contudo, entendendo a concepção de sujeito pela via do inconsciente, considerou a existência de estados depressivos como observados e descritos ao longo de algumas de suas obras. Em seu tempo, descreveu manifestações depressivas como as descritas na obra Luto e Melancolia por considerar um estado passível de revelar-se em diversos sofrimentos psíquicos intrínsecos à existência humana, sinalizando que o luto e a melancolia possuiriam características semelhantes diante da perda de um objeto.

Os traços mentais distintivos são um desânimo profundamente penoso, a cessação de interesse pelo mundo externo, a perda da capacidade de amar, a inibição de toda e qualquer atividade, e uma inibição dos sentimentos de autoestima (...) A perturbação da autoestima está ausente no luto, afora a isso, as características são as mesmas ${ }^{23}$.

Nesse contexto, o sentimento de autoestima não é perturbado pela consciência do objeto no que concerne aos estados depressivos. Ocorre nesses estados que a busca por recuperar o objeto perdido e a integridade narcísica, ocupa o tempo e o espaço do sujeito, obliterando "o prazer de viver, a capacidade de amar e de se relacionar"2.

Nessa perspectiva, embora a depressão não tenha ocupado um lugar de destaque na teoria freudiana, nos dias de hoje, ela pode ser compreendida como um modo de existir, uma condição em que o homem se vê impossibilitado para encontrar outra maneira de lidar com as exigências da sociedade atual ${ }^{24}$.

Vivemos em uma era que prega a fuga do sofrimento, a segurança, o sucesso, a felicidade, a busca por saúde e por satisfação dos desejos, ao passo que favorece a produção de uma sociedade que padece com o alastre e generalização da depressão e da sensação de $v a z i{ }^{25}$. A depressão seria o sinalizador do mal-estar na contemporaneidade, um sintoma social, tendo em vista que os depressivos seriam os atuais portadores de um saber a respeito das condições contemporâneas do malestar e, provavelmente, estariam em desajuste com as demandas que tal sociedade imporia ${ }^{7}$. Isso justificaria a atualidade das depressões e da sua expressão como um "sintoma social" possivelmente favorecendo o crescente número de diagnósticos de depressões na contemporaneidade. a depressão é sintoma social porque desfaz, lenta e silenciosamente, a teia de sentidos e de crenças que sustenta e ordena a vida social desta primeira década do século $\mathrm{XXI}$. Por isso mesmo, os depressivos, além de se sentirem na contramão de seu tempo, veem sua solidão agravar-se em função do desprestígio social de sua tristeza ${ }^{7}$.

O sintoma, portanto, expressaria algo da ordem do insuportável, uma dor que não consegue ser simbolizada, mas que precisa de um nome para dar concretude ao sofrimento, assim como saídas possíveis para o barrar. Para melhor compreensão do conceito de sintoma social, pode-se depreender que o sintoma seria mensagem cifrada de gozo e, por isso mesmo, seria a modalidade singular pela qual o sujeito goza. $O$ social seria o que daria universalidade aos sujeitos a partir da vida em cultura e dos limites impostos pela mesma sendo, por vezes, produtora de mal-estar por impossibilitar ao sujeito à não satisfação plena dos seus desejos.

A partir disso, ainda de acordo com a autora, o sintoma social situaria um campo que se articularia entre o universal da vida em cultura e o singular do sujeito, onde novas formas de subjetivações e novas modalidades de gozo surgiriam e ganhariam sentidos pelo discurso dominante de uma época ${ }^{26}$.

Do ponto de vista psicanalítico, o sintoma permitiria desse modo, acessar a organização simbólica que representa o sujeito, sendo, portanto, um signo que representaria alguma coisa ${ }^{12}$. No fluxo desse pensamento, o sintoma não se reduziria a sinal de doença, uma vez que diria da singularidade do sujeito. Esse modo de conceber o sujeito é "algo completamente diverso do observado hoje nos diagnósticos psiquiátricos, que nada dizem do sujeito em sua singularidade" 27 .

Assim, a abordagem psicanalítica considera que o sintoma não é apenas algo da ordem do individual, mas, sobretudo, constitutivo do funcionamento psíquico, mediante toda a complexidade social de nosso tempo. $O$ sujeito contemporâneo se constitui com base em uma série de referenciais produzidos pelas relações que operam dentro da sociedade. Desse modo, o discurso dos sujeitos traz em si as marcas dos referenciais construídos socialmente e das modificações ocorridas na própria subjetividade. Com isso, os olhares devem ser múltiplos para a compreensão desse sujeito, avaliando as suas crenças e identificações quando o mesmo fala 
do seu sofrimento, bem como as crenças que permeiam os diagnósticos de depressão. Apesar da multiplicidade de pacientes depressivos, não se pode perder a orientação psicanalítica de considerar a singularidade do sintoma de cada um. Assim, para psicanálise o sintoma seria uma metáfora, que por meio de significantes engendrados no discurso social dos sujeitos, poderia revelar os sentidos, os significados e as designações do sofrimento dos sujeitos, ou seja, diria de forma singular das suas dores.

\section{A ESCUTA PSICANALÍTICA NA SAÚDE MENTAL: DA UNIVERSALIDADE À SINGULARIDADE DO SUJEITO}

Nos dias de hoje, muitos sujeitos buscam atendimento na saúde pública para aliviar o seu sofrimento. As questões inerentes ao atendimento dos "deprimidos" atravessam $\circ$ cotidiano dos profissionais de saúde, principalmente dos que atuam de forma direta no trabalho com a saúde mental. Como já exposto a lógica capitalista e espetacular da contemporaneidade tem sido interpretada como condição para uma maior incidência dos estados depressivos de uma forma geral, uma vez que se observa nesse contexto transformações socioculturais que têm impactado na produção de novas formas de subjetivação.

Os dispositivos para atendimento clínico em saúde, especificamente os dispositivos de Saúde Mental, configurar-se-iam- como um lugar onde sujeitos podem buscar ajuda profissional para alívio dos seus mal-estares, uma vez que há alguém que o escute à sua dor ${ }^{6}$.

A reforma psiquiátrica, iniciada na década de 1970, teria possibilitado o surgimento de dispositivos de tratamento substitutivos ao modelo manicomial. A proposta da reforma reconfigurou $\circ$ quadro da assistência em Saúde Mental no Brasil a partir da criação dos Centros de Atenção Psicossocial (CAPS), das Residências Terapêuticas, dos Ambulatórios de Saúde Mental, entre outros dispositivos ${ }^{6}$.

Os CAPS compõem a Rede de Assistência Psicossocial
(RAPS) acolhendo os pacientes com transtornos mentais que apresentam intenso sofrimento psíquico, os quais, geralmente, se veem impossibilitados de viver e realizar seus projetos de vida. Os CAPS visariam estimular a integração social e familiar dos sujeitos, apoiando-os em suas iniciativas de construção da autonomia, oferecendo-lhes atendimento médico e psicológico ${ }^{28}$. Nessas instituições, os profissionais de saúde seriam responsáveis em construir um projeto terapêutico em colaboração com o usuário que está sendo atendido.

O trabalho nos CAPS deve se dar na articulação entre os profissionais que compõem a equipe multidisciplinar. A autora sublinha que nas práticas desses profissionais de saúde estariam presentes várias orientações clínicas, de acordo com a visão de mundo e de sujeito de cada um desses profissionais (28). Desse modo, essas práticas vão desde as que privilegiam a reabilitação psicossocial e o resgate dos direitos de cidadania dos usuários, até aquelas que tomam como eixo a singularidade do sujeito, por exemplo, a clínica de orientação psicanalítica, sendo essa uma das alternativas para o tratamento no contexto da saúde mental. Nessa direção, a psicanálise não seria uma teoria que se apresentasse unicamente como proposta epistemológica para o tratamento do sofrimento psíquico, podendo ser uma alternativa entre outras práticas que ocorrem na saúde pública, considerando a crescente interlocução da psicanálise com esses contextos ${ }^{29}$.

Na saúde pública, a entrada da psicanálise e consequentemente, da escuta psicanalítica, ocorreriam, geralmente, através do profissional psicólogo, fato ainda hoje comum, pois não existe nos quadros funcionais o cargo de psicanalista ${ }^{30}$.

A prática da psicanálise nos dispositivos de saúde mental teria como objetivo primordial propiciar uma escuta diferenciada a quem está em sofrimento, permitindo que os sujeitos falem de seu mal-estar com seus próprios significantes, o que na maioria das vezes não ocorre nos tratamentos psiquiátricos praticados nos dispositivos de saúde mental ${ }^{30}$.

A singularidade do sujeito na psicanalise é posta em relevo quando se pensa no tratamento oferecido, uma vez que se considera caso a caso e não se propõem tratamentos uniformes. Com relação às depressões, que $\circ$ atendimento psicológico nos 
CAPS comumente é um dos últimos recursos a ser procurado pelo paciente na tentativa de cura e alívio de seu sofrimento. Supõe-se que isso se deva a um desconhecimento das possibilidades da psicologia como tratamento por grande parte da população. Somado a isso, está a cultura medicalizante que traz uma ideia de alívio rápido para o sofrimento, perdendo-se aí a possibilidade de compreensão de que os estados depressivos fazem parte da existência humana, não necessariamente correspondendo a uma psicopatologia ${ }^{6}$.

A medicalização da depressão como prática frequente no contexto da saúde mental aponta para uma direção na qual se busca (re)mediar os sintomas, a ponto de se desconsiderar a dimensão subjetiva do mesmo. As bulas dos fármacos, por exemplo, mais especificamente dos antidepressivos, contêm uma descrição médica sobre o fenômeno da depressão ao passo que sugere promessas de cura terapêutica embutida em pílulas "mágicas". Ao fazer uso exclusivamente dessa possibilidade de tratamento, o sujeito, por vezes, coloca em suspensão o seu próprio rótulo de deprimido, mas sem livrar-se dele ou dar sentido ao seu sintoma, sustentando-se na farmacologia como alcance possível para alívio do seu sofrimento.

Desse modo, qual seria a contribuição da escuta psicanalítica aos sujeitos com queixa de depressão?) A escuta psicanalítica iria de encontro com a clínica do campo das especialidades médicas, "privilegiando o singular de cada caso, levando - mesmo a ressignificar o seu existir e tendo como efeito possível que o mesmo possa desalienar-se de rótulos psicopatológicos" 27 .

A escuta ao inconsciente significaria privilegiar as cadeias significantes primordiais que determinam no sujeito suas ações, suas fantasias, seus sintomas, ou seja, as vias por onde corre seu desejo. Porém, é importante considerar a escolha do sujeito no que se refere à adesão ou não ao tratamento, uma vez que existem várias concepções teóricas no contexto da saúde mental.

CAPS, observa-se que os sujeitos, plenamente identificados com seu diagnóstico de depressão, nem sempre estão dispostos ao trabalho pela via do inconsciente como uma das possibilidades de alívio para o seu sofrimento, tendo em vista que o sofrimento também pode se constituir como um modo de gozar. É nesse sentido a escuta do sujeito deve constituir-se a partir de uma relação terapêutica de confiança entre $\circ$ paciente e $\circ$ profissional que $\circ$ acompanha desde $\circ$ primeiro momento ${ }^{7}$.

Nessa relação, o sintoma apresentado pelo paciente, - profissional, cuja orientação é a psicanálise, deveria evitar o furor sanandi de exigir a suspensão do sintoma, uma vez que não se trata de barrar o sujeito, mas, mediante escuta e intervenções feitas pelo profissional, proporcionar o tempo subjetivo da experiência, cujas elaborações no processo de atendimento favoreçam ao sujeito se haver com o seu sintoma ${ }^{12}$.

Com efeito, a escuta psicanalítica nos dispositivos de saúde mental torna-se possível mediante o vislumbre de uma clínica que se amplia na interlocução com outros saberes e práticas dentro de uma equipe multiprofissional. A escuta psicanalítica nesse contexto não ganha contornos de sessões de análise, mas busca proporcionar ao sujeito a responsabilização por suas escolhas como ser desejante e por novos modos de se definir enquanto sujeito.

Por fim, ressalta-se que, além da saída farmacológica encontrada pelos sujeitos depressivos para lidar como seu sofrimento, faz-se necessário enfatizar que 0 atendimento psicológico na área da saúde, e mais especificamente no campo da Saúde Mental, configura-se como uma possibilidade dos sujeitos falarem de si, de seu sofrimento e do seu mal-estar. Isso requer que os profissionais da saúde tenham um olhar e uma escuta sensíveis para com os sujeitos que buscam atendimento.

\section{CONSIDERAÇÕES FINAIS}

O presente artigo pretendeu traçar um breve panorama dascaracterísticas da contemporaneidade que possivelmente teriam relação com o aumento dos diagnósticos de depressão na atualidade. Considerou-se as mudanças paradigmáticas, entre os referenciais que conduziam o sujeito em épocas passadas e o modo de vida que se estabelece na contemporaneidade (uma sociedade espetacular, 
narcisista, fluida e vazia de referenciais sólidos), como produtoras de mal-estares.

Desse modo, enfatizou-se que cada época criaria suas formas particulares de adoecimento que expressariam, de forma exacerbada, as estruturas da organização social vigente, dado que é sob as determinações da cultura que o mal-estar se constitui ${ }^{31}$. Assim sendo, os sujeitos contemporâneos provavelmente não reconhecem o sofrimento como processo intrínseco à condição humana, sucumbindo, por vezes, a (de)pressão e ao desejo perdido de seus ideais por não corresponderem às exigências da cultura de sua época.

Foi possível compreender que a psicanálise, por sua vez, interpreta os estados depressivos como sintomas que podem se manifestar em qualquer momento da vida do sujeito considerando a sua inserção na cultura. Ao lado disso, percebeu-se que os malestares contemporâneos são rapidamente tratados como uma possível doença, como o que ocorre na depressão. Reconhece-se dessa forma que lidar com os mal-estares na sociedade contemporânea parece não ser tarefa fácil, levando os sujeitos a fazerem escolhas que aliviem o sofrimento de forma rápida, na mesma rapidez do tempo no qual se vive. $O$ que se observa é que a contemporaneidade pode ser vista como uma era que não favorece um "tempo para sofrer", assim como não há tempo para o sujeito se envolver com o seu próprio malestar, buscar suas causas, responsabilizar-se pelo seu sintoma e construir novas maneiras de lidar com ele.

Na tentativa de extirparo mal-estar, busca-se soluções rápidas que não permitem qualquer elaboração subjetiva, lançando mão de medicamentos psicotrópicos como alternativa possível para os mal-estares. Nesse contexto, surge o fenômeno da medicalização do sofrimento, tão facilmente observado nos dias de hoje. Uma medicalização (des)medida na intensidade do sofrimento, haja vista que quanto maior a dor, aqui compreendida como dor de existir, mais recursos farmacológicos são usados, tendo em vista que o sujeito busca estar em acordo com alguns imperativos da sociedade atual: Não sofra! Satisfação já! Seja feliz!

É importante frisar que não se buscou resumir os sujeitos aos seus sintomas, nem desconsiderar os benefícios dos fármacos psicotrópicos e a importância da psiquiatra no tratamento da depressão. $O$ que se ressalta aqui é que os sintomas fazem parte, eles mesmos, da estrutura discursiva dos sujeitos e que o uso indiscriminado e excessivo dos medicamentos, pode favorecer com que o sujeito desapareça e seja visto tão somente como uma patologia, como acontece por vezes no modelo biomédico psiquiátrico.

Conclui-se que a escuta é um instrumento essencial do trabalho clínico e psicossocial, na medida em que falar pressupõe um endereçamento ao outro e, portanto, um engendramento do laço social. A escuta clínica oportuniza ao sujeito falar de si e do seu sofrimento, dando mobilidade ao campo do simbólico e aos profissionais da saúde, uma vez que lhes possibilita mais sensibilidade no trato com - sofrimento dos sujeitos. A escuta psicanalítica, no campo da saúde mental, entra como uma das práticas dentre tantas outras de tratamento nesse contexto, posicionando-se de forma distinta na contemporaneidade diante das novas formas de subjetivações, dos sofrimentos, ou seja, dos sintomas enquanto efeitos do social.

\section{REFERÊNCIAS}

1. Sigmund F. O mal-estar na civilização (1931). In: Edição Standart Brasileira das Obras Psicológicas Completas de Sigmund Freud. Rio de Janeiro: Imago; 2006

2. Debord G. A sociedade do espetáculo. Rio de Janeiro: Contraponto; 1997

3. Bauman Z. O mal-estar da Pós-Modernidade. Rio de Janeiro: Jorge Zahar; 1998

4. Tavares LAT, Hashimoto F. A relativa legitimidade da depressão na atualidade: contribuições para uma ética psicanalítica do sujeito. Lat. Am. Journal Of Fund. Psychopath. 2010;7(1):88-100

5. OMS. Organização Mundial da Saúde. Relatório Mundial da Saúde. Saúde mental: nova concepção, nova esperança [Internet]. Disponível em: http://www. who.int/whr/2001/en/whr01_dimessage_po.pdf 
6. Tavares LAT. A depressão como "mal-estar" contemporâneo: medicalização e (ex)-sistência do sujeito depressivo [Dissertação]. São Paulo: Editora UNESP; 2010

7. Kehl MR. O tempo e o cão: a atualidade das depressões. São Paulo: Boitempo; 2009

8. Ewald AP, Moura MTC, Goulart SMS.

Contemporaneidade e sofrimento psíquico: Relações entre modos de vida e demandas psicoterapêuticas. Psicol. Argum. 2012; 30(68):1 19-129

9. Bauman Z. Modernidade Líquida. Rio de Janeiro: Jorge Zahar; 2001

10. Birman J. Laços e desenlaces na contemporaneidade. J. psicanal. 2007;40(72):47-62

11. Mendes ED, Paravidini JLL. Os significantes da escuta psicanalítica na clínica contemporânea. Psyche. 2007;1 1(20):99-116

12. Quinet A. Psicose e laço social. Rio de Janeiro: Jorge Zahar; 2006

13. Vieira AS. O inspira (dor) mundo moderno: notas sobre melancolia na atualidade. Revista O Olho da História: $\mathrm{n}^{\circ} 22$ [Internet]. 2016 [Acesso 29 de abril de $2016]$. Disponível em: http://oolhodahistoria.ufba.br/ wp-content/uploads/2016/04/antonia.pdf

14. Esteves FC, Galvan AL. Depressão numa contextualização contemporânea. Aletheia. 2006;(24):1 27-135

15. Freud S. Inibição, Sintoma e Angústia (1926 [1925]. In: Edição Standart Brasileira das Obras Psicológicas Completas de Sigmund Freud. Rio de Janeiro: Imago; 2006

16. Freud S. Sobre o conceito de narcisismo: uma introdução (1914). In: Edição Standart Brasileira das Obras Psicológicas Completas de Sigmund Freud. Rio de Janeiro: Imago; 1996

17. Quintella RR. Vicissitudes da Crença Narcísica: a Depressão no Mundo Contemporâneo. [Tese de Doutorado]. Rio de Janeiro: Programa de PósGraduação em Teoria Psicanalítica; 2008

18. Lacan J. A direção do tratamento e os princípios do seu poder (1964). In. Escritos Trad. Vera Ribeiro. Rio de janeiro: Jorge Zahar; 1998. P. 585 -562

19. Camargo SG. Tristeza ou depressão? Uma impropriedade significante. Sephora. 2008;3(5): 1 -7

20. Baptista MCF. Melancolia, depressão e dor de existir. Revista Hospital Universitário Pedro Ernesto. $2011 ; 10(2): 21-30$

21. Daniel C, Souza M. Modos de subjetivar e de configurar o sofrimento: depressão e modernidade. Psicologia em Revista. 2006;1 2(20):1 17-130

22. Dalgalarrondo P. Psicopatologia e Semiologia dos Transtornos Mentais. Porto Alegre: Editora Artes Médicas do Sul; 2000

23. Freud S. Luto e melancolia. (1914) in: Edição Standart Brasileira das Obras Psicológicas Completas de Sigmund Freud. Rio de Janeiro: Imago; 1996

24. Delouya D. Depressão. São Paulo: Casa do Psicólogo; 2002

25. Perez M, Sirelli NM. A medicalização do mal-estar: a escuta psicanalítica como um modo de resistência. Psicanálise \& Barroco em revista. 2015;13(2):1 17-136

26. Vorcaro A. Seria a toxicomania um sintoma social? Mental, Barbacena. 2004;2(3):61-73

27. Silva S. A clínica da histeria no CAPS: escutar o sujeito entre outros [Dissertação]. Belém: Universidade Federal do Pará. Instituto de Filosofia e Ciências Humanas; 2012

28. Rinaldi D. Entre o sujeito e o cidadão: psicanálise ou psicoterapia no campo da saúde mentale In: Alberti S, Figueiredo AC. (Orgs.). Psicanálise e saúde mental: uma aposta. Rio de Janeiro: Companhia de Freud; 2006. P. $141-147$

29. Andrade F, Lessa L. O trabalho psicanalítico no ambulatório do Hospital Juliano Moreira: reflexões sobre a clínica do sujeito [Tese de Doutorado]. Bahia: Instituto de Psicologia. Universidade Federal da Bahia; 2013

30. Victor RM, Fernando A. A clínica Psicanalítica na Saúde Pública: desafios e possibilidades. Psicol. Cienc. Prof., Brasília. 2011 ;31 (1):40-49

31. Lasch C. A Cultura do narcisismo: a vida Americana numa era de esperanças em declínio. Rio de Janeiro: Imago; 1983 